\title{
Diagnostic and mechanistic implications of serum free light chains, albumin and alpha-fetoprotein in hepatocellular carcinoma
}

\author{
M Teng ${ }^{1}$, S Pirrie ${ }^{1}$, D G Ward ${ }^{1}$, L K Assi ${ }^{2}$, R G Hughes ${ }^{2}$, D Stocken ${ }^{1}$ and P J Johnson ${ }^{\star, 1,3}$ \\ ${ }^{1}$ Cancer Research UK, Institute for Cancer Studies, School of Cancer Sciences, University of Birmingham, Vincent Drive, Edgbaston \\ B15 2TT, UK and ${ }^{2}$ The Binding Site Group Limited, 8 Calthorpe Road, Edgbaston B15 1QT, UK
}

\begin{abstract}
Background: Mass spectroscopy analysis suggested low serum albumin and high immunoglobulin free light chain (sFLC) levels may have diagnostic value in hepatocellular carcinoma (HCC). Our aims were to apply quantitative assays to confirm these observations, determine their diagnostic utility, and investigate the mechanisms involved.
\end{abstract}

Methods: Albumin, sFLC, routine liver and renal function tests were measured in patients with chronic liver disease with $(n=102)$ and without $(n=113)$ HCC. The discriminant performance was compared with the current standard serological test alphafetoprotein (AFP) using receiver operating characteristic (ROC) and area under the curve (AUC) analyses.

Results: sFLC and serum albumin were each confirmed to have discriminatory utility in HCC with AUC values of 0.7 and 0.8 , respectively. sFLC were strongly correlated with gammaglobulin levels and both these were inversely related to serum albumin levels. The discriminatory utility of sFLC was retained after adjusting for renal and liver function.

Conclusions: Serum levels of sFLC and albumin were strongly associated with HCC as predicted by mass spectroscopy. Discrimination of HCC by AFP was improved by the addition of either albumin or sFLC. Larger prospective studies are required to determine how AFP, sFLC and albumin might be combined in a useful diagnostic approach for HCC.

Early diagnosis of hepatocellular carcinoma (HCC) is widely considered to be the key to effective therapy. Radical, potentially curative treatments, such as surgical resection, radiofrequency ablation and orthotopic liver transplantation are only applicable to that minority of patients who present with, or who are detected by screening to have, smaller tumours, typically $<5 \mathrm{~cm}$ in diameter (Bruix and Sherman, 2005). This observation has led to routine screening/surveillance of patients at high risk of HCC, namely those with advanced chronic liver disease and certain carriers of the hepatitis B or C viruses (HBV, HCV). Both in the screening situation and the clinical situation where it is required to determine if HCC has developed in a patient with symptoms, an imaging procedure, usually ultrasound, followed by a CT or MRI are the primary diagnostic modalities supplemented where necessary with histological confirmation by biopsy (Bruix and Sherman, 2005). Characteristic imaging features such as arterial enhancement and portal phase 'washout' have been recognised to be highly sensitive and specific features for the diagnosis of HCC (Torzilli et al, 1999; Sangiovanni et al, 2010). Nonetheless, such an approach is expensive and ultrasound examination is time-consuming and highly operator-dependent so, a simple serological diagnostic test would be invaluable. Estimation of serum alpha-fetoprotein (AFP) has been widely used in this respect and indeed it is well recognised to be highly specific and useful in the clinical setting when levels are elevated above a particular threshold typically set between 200 and $500 \mathrm{ng} \mathrm{ml}^{-1}$ (Johnson, 2001). However, the role of AFP in the screening setting remains controversial, some supporting its utility (Marrero and El-Serag, 2011) and others, because of its low

*Correspondence: Professor PJ Johnson; E-mail: Philip.Johnson@liverpool.ac.uk

${ }^{3}$ Current address: University of Liverpool and Clatterbridge Cancer Centre NHS Foundation Trust.

Received 2 October 2013; revised 15 January 2014; accepted 11 February 2014; published online 6 March 2014 
sensitivity in the early stages of the disease, have suggested that AFP has no role in the screening setting (Bruix and Sherman, 2005; Bruix and Sherman, 2011).

In a search for an alternative or additional serum markers for HCC, we and others (Poon et al, 2003; Schwegler et al, 2005; Ward et al, 2006b) have used surface-enhanced laser desorption/ ionisation (SELDI) mass spectroscopy to profile the serum proteomes of patients with HCC and chronic liver disease and those with chronic liver disease alone with a view to identify a specific HCC signature. Although our studies showed that, in principle, there was a characteristic 'signature', the early studies did not identify the proteins responsible for the discrimination and as such were regarded as 'black box' models (Poon et al, 2003). Subsequently, in a study of hepatitis C-related HCC, we developed a model that appeared to have high sensitivity and specificity and that performed well on an independent test set (Ward et al, 2006a). Furthermore, we identified the most discriminatory of the identified peaks as representing serum immunoglobulin free light chains (sFLC) and albumin. Recognising that the spectroscopic profiling techniques for measuring these proteins were only semiquantitative, and that is difficult to envisage a plausible explanation for the apparent diagnostic value of sFLC or albumin, the model was not pursued further.

More recently, a sensitive assay for sFLC has become available (Bradwell et al, 2001) and it has been shown that concentrations of sFLC are elevated in chronic liver disease (Assi et al, 2010). We have, therefore, revisited this area to examine the extent to which the mass spectroscopy-based prediction of diagnostic utility could be confirmed when specific assays were used.

\section{MATERIALS AND METHODS}

Hundred and two subjects with HCC were recruited from patients referred to the Queen Elizabeth Hospital, Birmingham, UK. For all the patients, the diagnosis was established by histology or the combination of characteristic radiology together with an elevated AFP level according to international guidelines (Bruix and Sherman, 2005). Control samples were recruited from 113 patients who were attending out-patient clinics for chronic liver disease in the same institution. The various aetiologies were classified as HBV-related, HCV-related, alcoholic-related and other. The latter group comprised patients with haemochromatosis, primary biliary cirrhosis, non-alcoholic steatohepatitis, or cryptogenic cirrhosis. The diagnosis of chronic liver disease was made on the basis of liver biopsy and/or typical clinical and imaging features. None of the control groups had evidence of HCC at the time when the sample was taken or with a follow-up period of 9 months.

Samples were collected with full informed consent and after approval by the local ethics committee, prospectively and specifically for the purpose of biomarker discovery and validation. Routine liver and renal function tests (including cystatin C) were measured and the severity of the liver disease was defined according to the Child's classification (Child and Turcotte, 1964; Pugh et al, 1973) and the model for end-stage liver disease (MELD) score (Kamath and Kim, 2007). Standard liver and renal function tests were measured using the Roche Modular Analytics system (Roche Diagnostics Ltd, Burgess Hill, UK). Hepatitis B surface antigen and anti HCV were measured using the Roche Hepatitis system.

Samples were assessed for total IgG, total $\operatorname{IgA}$ and total IgM (Dade Behring, Siemens, Germany), serum free kappa (FLC $\kappa$ ) and serum free lambda (FLC $\lambda$ ) light chains (Freelite, The Binding Site Group Ltd, Birmingham, UK) and cystatin C (The Binding Site Group Ltd). The reference range used for the sFLC analysis were: FLC $\kappa$ 3.3-19.4 $\mathrm{mgl}^{-1}$, FLC $\lambda$ 5.71-26.3 $\mathrm{mgl}^{-1}$ and FLC ratio
0.26-1.65 (Katzmann et al, 2002). The reference range for cystatin $\mathrm{C}$ was $0.56-0.99 \mathrm{mgl}^{-1}$ and the reference range for IgG, IgA and IgM were $6-16 \mathrm{gl}^{-1}, 0.8-4 \mathrm{gl}^{-1}$ and $0.5-2 \mathrm{gl}^{-1}$, respectively (Ward et al, 2004).

Statistical analysis. Statistical analysis was conducted using Stata11 (StataCorp, College Station, TX, USA). The distribution of FLC $\kappa$ and FLC $\lambda$ was plotted in box and whisker format. One extreme value of FLC $\kappa\left(592 \mathrm{mgl}^{-1}\right)$ with a highly abnormal FLC ratio of 619 suggesting undiagnosed multiple myeloma/B-cell dyscrasia was excluded. In descriptive statistics, Mann-Whitney $U$ test was used to assess the difference in distribution of sFLC and albumin between the HCC and the control group. Logarithmic transformation was applied to transform skewed data to correct for overdispersion. Univariate analysis was performed for each potential biomarker and serum parameter. Receiver operating characteristic (ROC) analysis was used to assess the discriminant performance of various biomarkers alone and in combination by comparing the area under the curve (AUC). Serum AFP was used as the current standard serological test for comparison and as a baseline to determine whether sFLC or albumin could add discriminatory power. A $P$-value of $<0.05$ was considered statistically significant.

\section{RESULTS}

There was a highly significant increase in the concentration of both FLC $\kappa$ and FLC $\lambda$ in the HCC patients (median of $34.81 \mathrm{mgl}^{-1}$ and $32.50 \mathrm{mgl}^{-1}$ for the HCC patients $v s 18.20 \mathrm{mgl}^{-1}$ and $18.20 \mathrm{mgl}^{-1}$ for the control group, respectively, $P<0.0001$, Mann-Whitney $U$ test) (Figure $1 \mathrm{~A}$ and B). Serum albumin levels were signficantly lower in the HCC patients (medians of $37 \mathrm{gl}^{-1}$ in the HCC group and $45 \mathrm{gl}^{-1}$ in the control group, $P<0.0001$, Mann-Whitney $U$ test) (Figure 1C). Levels of sFLC varied with disease aetiology. In particular, the elevation of both FLC $\kappa$ and FLC $\lambda$ was most marked in HCV-positive HCC patients (Figure $1 \mathrm{~A}$ and $\mathrm{B}$ ).

Both albumin and either of the light chains had discriminatory power with AUC ROC values between 0.73 and 0.77 , respectively (Figure 2). We then used multivariant logistic regression analysis to assess the impact of sFLC when adjusted for individuals' renal function (as measured by creatinine or cystatin C) and/or liver function (as measured by bilirubin, INR, or MELD). Both cystatin $\mathrm{C}$ and MELD were significant in univariate analyses but both dropped out of the model at $95 \%$ significance when either of the sFLC were included into the model. Being aware that the standard serological marker for HCC was serum AFP, we then examined the extent to which either of the light chains or serum albumin increases the diagnostic accuracy of AFP. The AUCs of FLC $\kappa$ and FLC $\lambda$ were 0.91 and 0.90 , respectively, when each was individually combined with AFP (Figure 3). However, their impact was no longer significant when serum albumin was included into the model. The simple combination of albumin $(\mathrm{AUC}=0.77)$ and AFP $(A U C=0.87)$ was marginally more effective, than sFLC, with an AUC of 0.92 (Figure 3).

As noted in Figure 1, most values within the control group fell within the reference range, but in the HCC group, levels were signifcantly higher across all aetiology groups. Gamma globulin was moderately directly related to both FLCs ( $\kappa$ and $\lambda$ ) with an $R^{2}$ figure of 0.37 and 0.33 , respectively, while it was moderately inversely related to serum albumin with an $R^{2}$ value of 0.34 (Figure 4A-C).

Finally, we explored the relationship between serum albumin and gamma globulin as assessed by the difference between total protein and albumin, or by individual immunoglobulin subgroups, that is, IgG, IgA and IgM. There was a moderate inverse 

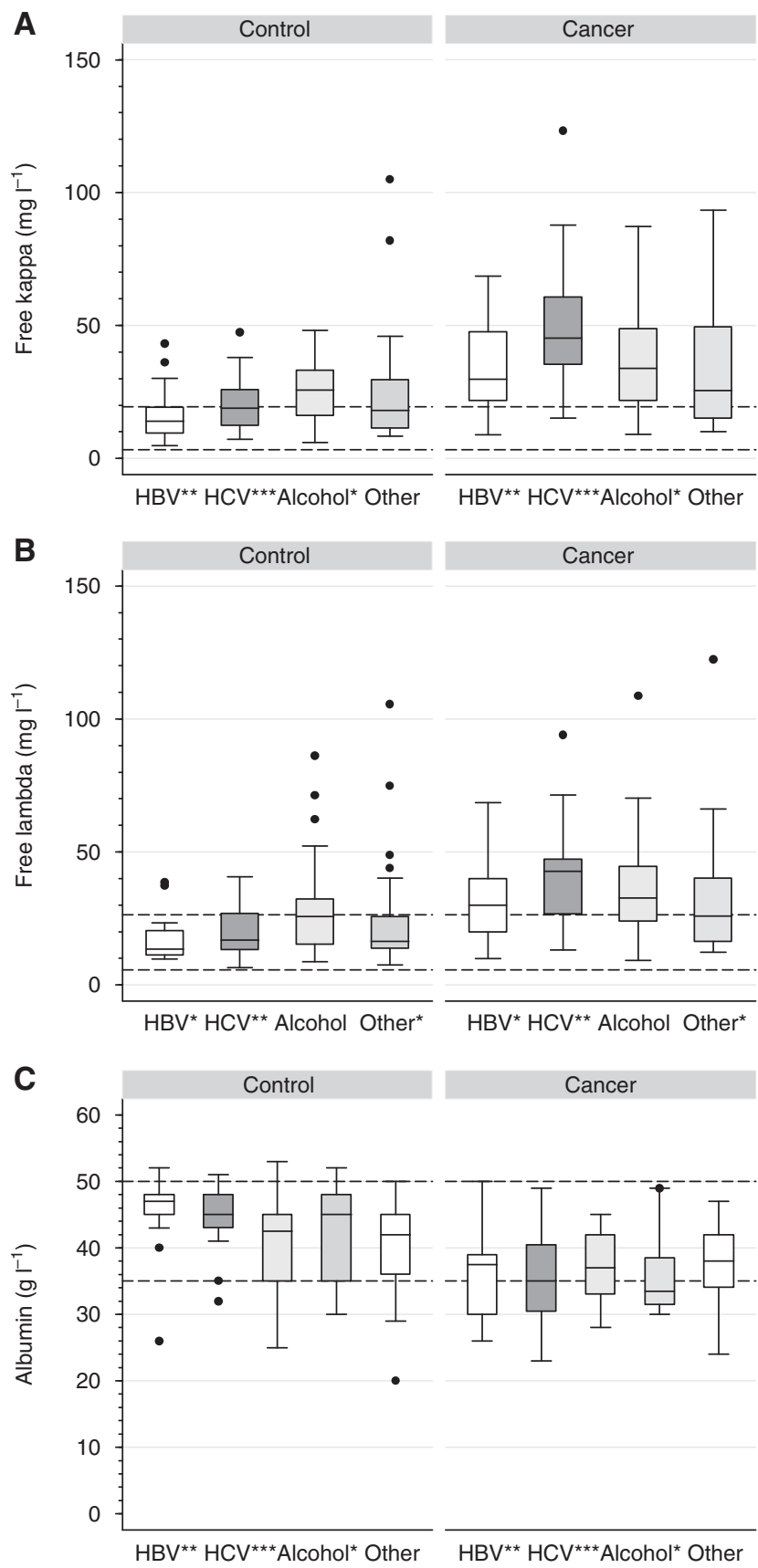

Figure 1. Serum levels of (A) free kappa, (B) free lambda light chains and $(\mathbf{C})$ albumin in relation to disease aetiology. Mann-Whitney $U$ test was used to assess the differences in distribution between HCC (Cancer, $n=102)$ and the control group $(n=113)$ within the same aetiology group. ( ${ }^{\star} P<0.05,{ }^{\star \star} P<0.005$ and ${ }^{\star \star \star} P<0.0005$ ). Dashed lines indicate the upper and the lower reference values.

relationship between serum albumin and the difference between total protein and albumin (i.e., the gamma globulin fraction) with an $R^{2}$ value of 0.42 (Figure $5 \mathrm{~A}$ ). Among all the immunoglobulins, the relationship of IgG and albumin was most akin to the overall gamma globulin in relation to albumin as indicated by equal slopes (Figure 5B).

\section{DISCUSSION}

The data presented here validate the conclusions of our original SELDI study using quantitative assays in a large independent

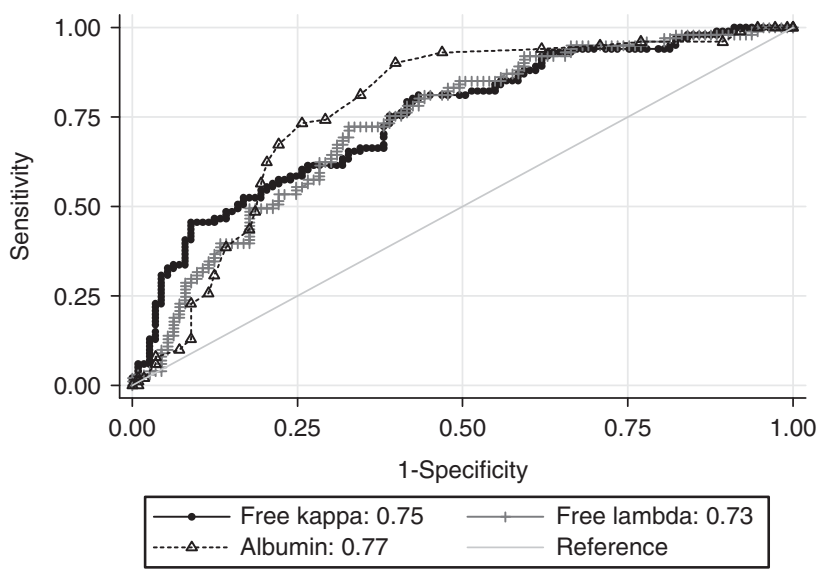

Figure 2. ROC curves for serum free kappa, serum free lambda and albumin.

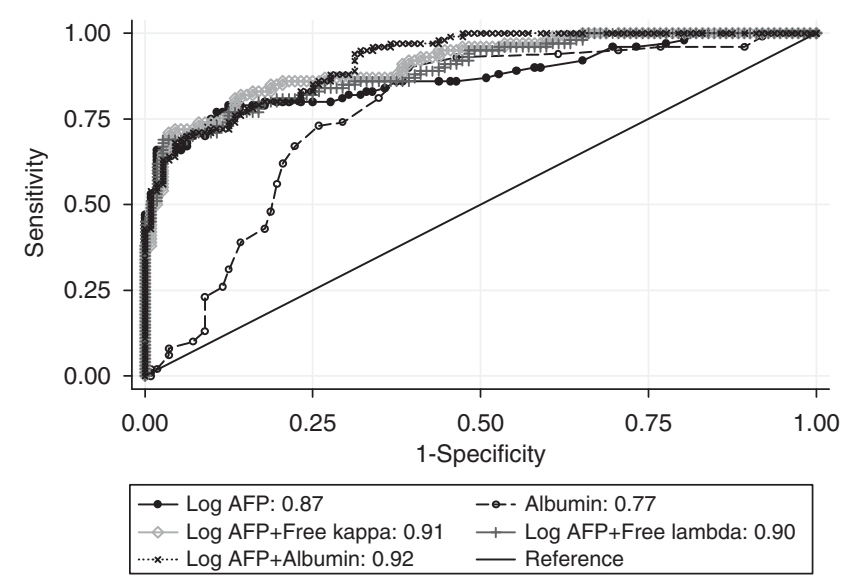

Figure 3. ROC curve for serum albumin and AFP and their combinations.

patient cohort (Ward et al, 2006a). We confirm that the most significant changes identified by SELDI (albumin and sFLC) (Ward et al, 2006a) indeed do have a considerable discriminatory potential.

AFP is the standard serological test for HCC and returned an AUC value of 0.87 . By simply combining either albumin or sFLC with AFP, an impressive AUC ROC value of $>0.90$ was obtained. However, sFLC concentrations correlated closely with albumin, and combining sFLC and albumin with AFP did not further improve the AUC. Serum AFP and albumin are simple, cheap and are routinely used in hospital laboratories for the assessment of liver disease (Carr et al, 2007; Leerapun et al, 2007; Sterling et al, 2007). Therefore, these observations indicate that albumin used in combination with AFP, might be a useful diagnostic screening test for HCC, although this would require further validation in larger prospective studies.

A low serum albumin level has been consistently associated with a markedly increased risk of HCC. Thus, Wong et al, (Wong et al, 2010) using a large prospective cohort of patients with HBVrelated chronic liver disease, showed that low serum albumin, at the time of entry into the study, was a key determinant of subsequent HCC development. Nagao and Sata (Nagao and Sata, 2010) reported that, in a population-based study, in an area of high HCV endemicity, hypoalbuminaemia was associated with significantly increased mortality, particularly from HCC. Bonis et al (1999) similarly found albumin to be a predictive factor for HCC development among a large group of patients with chronic 

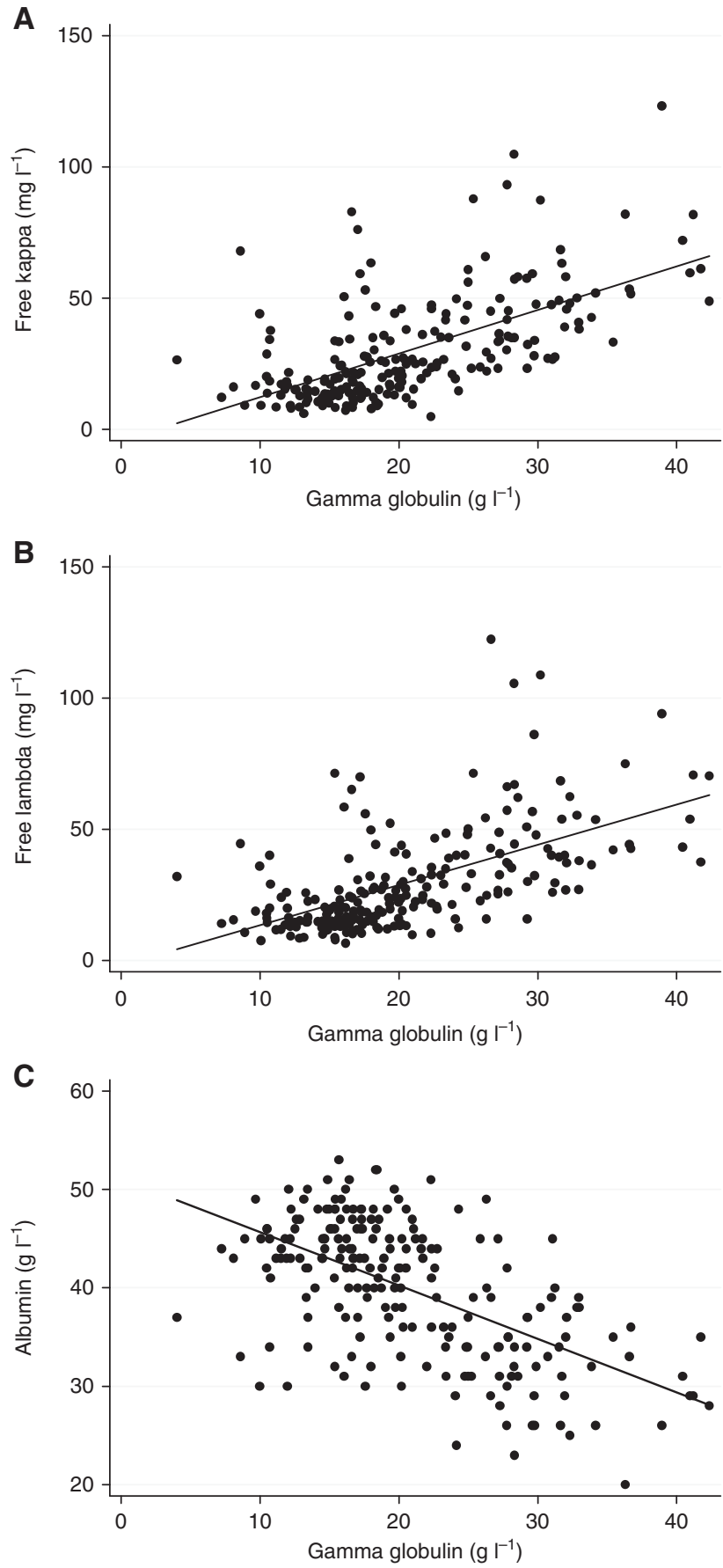

Figure 4. Correlation between gammaglobumin and (A) serum free kappa, (B) serum free lambda and (C) albumin.

hepatitis $\mathrm{C}$ infection. Above an albumin level of $41 \mathrm{gl}^{-1}$, the risk of HCC was only $3 \%$ compared with $40 \%$ for an albumin level below $41 \mathrm{gl}^{-1}$. These authors considered a standard hepatological interpretation of hypoalbuminaemia, that is, a reflection of poor synthetic liver function (Schuppan and Afdhal, 2008). Others, however, have questioned this and suggested that the hypoalbuminaemia may be related to the level of hypergammaglobulinaemia as depression of albumin is consistent across a wide range of diseases and inversely proportional to the gamma globulin levels (Keshgegian, 1984). This was the case in the present study, both in the HCC patients, the control subjects and in the group as a whole. The reason for an elevation of gamma globulin in chronic liver disease is again unclear, but seems likely to reflect an increased
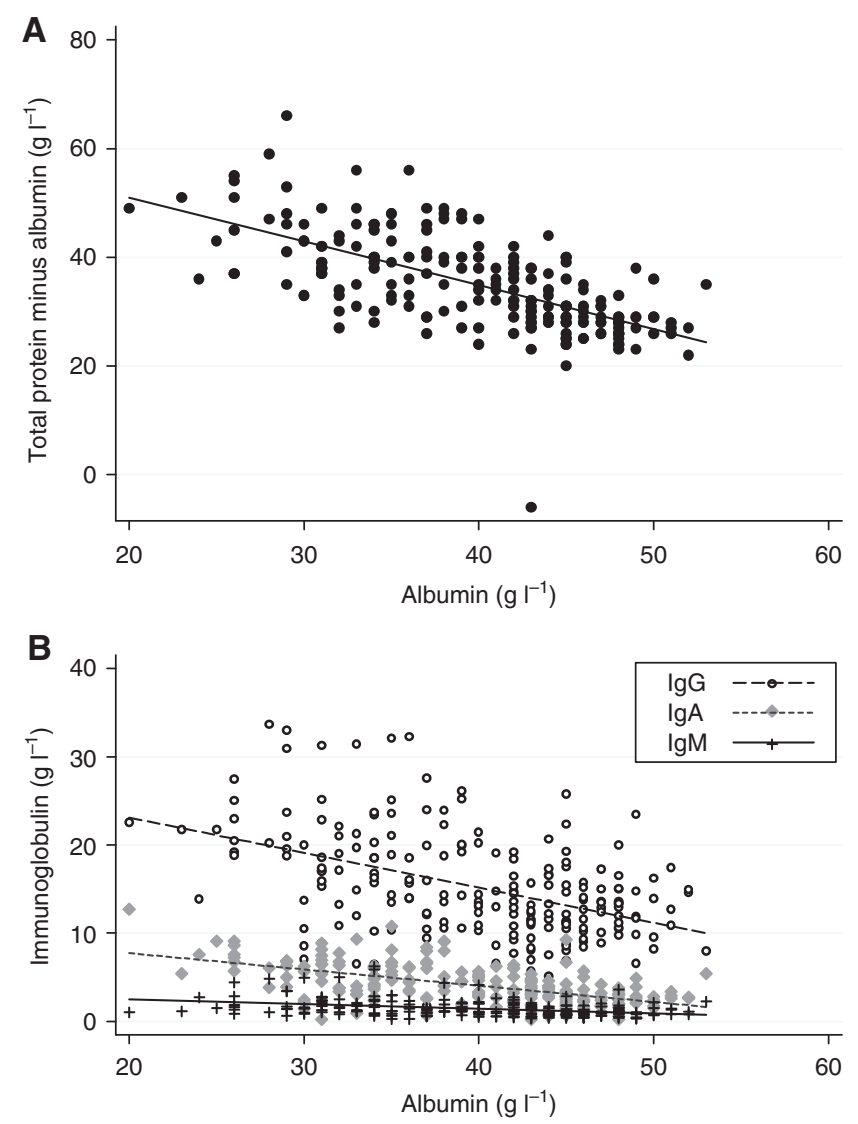

Figure 5. Correlation between albumin and (A) total gamma globulin and $(B)$ individual immunoglobulins ( $\lg A, \lg M$ andlgG).

exposure of gastrointestinal antigens to the systemic circulation as a result of portal hypertension.

Elevated sFLCs occur in several chronic conditions particularly those with generalised B-cell activation including systemic lupus erythematosus (Aggarwal et al, 2011), rheumatoid arthritis and Sjörgrens syndrome (Gottenberg et al, 2007), and have been shown to correlate significantly with disease activity (Aggarwal et al, 2011). Elevated sFLC have also been shown to be associated with an increased risk of non-Hodgkin's lymphoma in patients with HCV (Terrier et al, 2009) or HIV (Landgren et al, 2010), and are associated with poorer overall survival in chronic lymphocytic leukaemia patients (Maurer et al, 2011). The association between disease activity and sFLC was stronger than for immunoglobulin levels, suggesting that sFLC may act as more sensitive surrogate markers of B cell function (Landgren et al, 2010; Aggarwal et al, 2011).

In the current study, sFLC concentrations were significantly elevated in the HCC patients, who were HBV or HCV-positive. Antibodies to HBV and HCV viral epitopes are more frequently detected in patients with HCC than in patients with cirrhotic liver disease and are often evident before the development of HCC and prior to elevations in AFP (Hann et al, 2004). Elevated sFLC may reflect the developing B-cell response to viral infection and could provide an early marker of HCC onset in virally infected patients. In addition, as sFLCs have been implicated in the induction of chronic inflammatory disease, and have been shown to bind to carcinoma cells (van der Heijden et al, 2006) and other intracellular and extracellular proteins (van der Heijden et al, 2006), sFLC could potentially influence the onset of HCC. Further work is required to elucidate the role of sFLC in HCC.

Overall, there are two possible interpretations of our data. Firstly, low serum albumin, as a result of poor 'synthetic liver 
function' is compensated for by a rise in gamma globulin as a homoeostatic response to maintain plasma oncotic pressure and that the elevation of sFLC is simply a consequence of this hypergammaglobulinaemia. Alternatively, as suggested by Keshgegian (1984), the primary event may be the hypergammaglobulinaemia. In any event, this interpretation would suggest that any of these three parameters (low albumin, and raised gamma globulins or sFLC) somehow reflect an aspect of liver function that is permissive to HCC development.

The observation that a combination of albumin and AFP both appear to have some diagnostic utility individually, but more so in combination, one rising and one falling in the presence of HCC, may still be noteworthy as the two proteins have a high degree of sequence homology (Law and Dugaiczyk, 1981; Belanger et al, 1994). AFP is often described as 'fetal albumin'. Thus, levels of albumin are low in the fetus but rise rapidly, immediately after birth, whereas our current results appear to suggest the reverse happens during malignant change. It is conceivable that the rise in AFP and fall in albumin represents a recapitulation of the fetal state or a block in differentiation during malignant change, at the fetal stage.

In conclusion, we have identified two easily quantifiable serum markers that can be combined individually with AFP to improve the discrimination of HCC patients from patients with chronic liver disease. However, an important question to address is, to what extent albumin and sFLC changes may address the limited sensitivity of AFP for early HCC detection. This would require suitable diagnostic thresholds to be established for each marker. Additional prospective studies are required to determine how a combination of albumin, sFLC and AFP may be used to predict risk of HCC onset or to identify cirrhotic patients at a higher risk of developing HCC, who would benefit from more frequent surveillance.

\section{ACKNOWLEDGEMENTS}

The collection of serum samples and clinical data was supported in part by the Birmingham Biomedical Research Unit and the Birmingham Experimental Cancer Medicine Centre. The Binding Site Group Ltd. provided kits free of charge. The authors would like to thank Janet Morse (Institute of Cancer Research, University of Birmingham) for collecting the serum samples, Bridget Gunson (Centre for Liver Research, University of Birmmingham) for providing additional diagnostic data, and Jeffrey Faint (The Binding Site Group Ltd) for critically reading the manuscript.

\section{CONFLICT OF INTEREST}

LKA and RGH are employees of The Binding Site Group Ltd. The remaining authors declare no conflict of interest.

\section{AUTHORS CONTRIBUTIONS}

PJJ, RGH conceived the original idea and designed the study with LKA. MT, DGW and LKA collected the data for the study, which was analysed by MT, DS and SP. The manuscript was written by PJJ. All authors reviewed the manuscript and gave final the approval for submission.

\section{REFERENCES}

Aggarwal R, Sequeira W, Kokebie R, Mikolaitis RA, Fogg L, Finnegan A, Plaas A, Block JA, Jolly M (2011) Serum free light chains as biomarkers for systemic lupus erythematosus disease activity. Arthritis Care Res 63(6): 891-898.

Assi LK, Hughes RG, Gunson B, Webb GM, Drayson MT, Bradwell AR, Adams DH (2010) Abnormally elevated serum free light chains in patients with liver disease. J Hepatol 51(s1): S440-S441.

Belanger L, Roy S, Allard D (1994) New albumin gene 3' adjacent to the alpha 1-fetoprotein locus. J Biol Chem 269(8): 5481-5484.

Bonis PA, Tong MJ, Blatt LM, Conrad A, Griffith JL (1999) A predictive model for the development of hepatocellular carcinoma, liver failure, or liver transplantation for patients presenting to clinic with chronic hepatitis $\mathrm{C}$. Am J Gastroenterol 94(6): 1605-1612.

Bradwell AR, Carr-Smith HD, Mead GP, Tang LX, Showell PJ, Drayson MT, Drew R (2001) Highly sensitive, automated immunoassay for immunoglobulin free light chains in serum and urine. Clin Chem 47(4): 673-680.

Bruix J, Sherman M (2005) Management of hepatocellular carcinoma. Hepatology 42(5): 1208-1236.

Bruix J, Sherman M (2011) Management of hepatocellular carcinoma: an update. Hepatology 53(3): 1020-1022.

Carr BI, Kanke F, Wise M, Satomura S (2007) Clinical evaluation of lens culinaris agglutinin-reactive alpha-fetoprotein and des-gamma-carboxy prothrombin in histologically proven hepatocellular carcinoma in the United States. Dig Dis Sci 52(3): 776-782.

Child CG, Turcotte JG (1964) Surgery and portal hypertension. In The liver and portal hypertension, Child CG (ed). pp 50-64.

Gottenberg JE, Aucouturier F, Goetz J, Sordet C, Jahn I, Busson M, Cayuela JM, Sibilia J, Mariette X (2007) Serum immunoglobulin free light chain assessment in rheumatoid arthritis and primary Sjogren's syndrome. Ann Rheum Dis 66(1): 23-27.

Hann HW, Lee J, Bussard A, Liu C, Jin YR, Guha K, Clayton MM, Ardlie K, Pellini MJ, Feitelson MA (2004) Preneoplastic markers of hepatitis B virus-associated hepatocellular carcinoma. Cancer Res 64(20): 7329-7335.

Johnson PJ (2001) The role of serum alpha-fetoprotein estimation in the diagnosis and management of hepatocellular carcinoma. Clin Liver Dis 5(1): 145-159.

Kamath PS, Kim WR (2007) The model for end-stage liver disease (MELD). Hepatology 45(3): 797-805.

Katzmann JA, Clark RJ, Abraham RS, Bryant S, Lymp JF, Bradwell AR, Kyle RA (2002) Serum reference intervals and diagnostic ranges for free kappa and free lambda immunoglobulin light chains: relative sensitivity for detection of monoclonal light chains. Clin Chem 48(9): 1437-1444.

Keshgegian AA (1984) Hypoalbuminemia associated with diffuse hypergammaglobulinemia in chronic diseases: lack of diagnostic specificity. Am J Clin Pathol 81(4): 477-481.

Landgren O, Goedert JJ, Rabkin CS, Wilson WH, Dunleavy K, Kyle RA, Katzmann JA, Rajkumar SV, Engels EA (2010) Circulating serum free light chains as predictive markers of AIDS-related lymphoma. J Clin Oncol 28(5): 773-779.

Law SW, Dugaiczyk A (1981) Homology between the primary structure of alpha-fetoprotein, deduced from a complete cDNA sequence, and serum albumin. Nature 291(5812): 201-205.

Leerapun A, Suravarapu SV, Bida JP, Clark RJ, Sanders EL, Mettler TA, Stadheim LM, Aderca I, Moser CD, Nagorney DM, LaRusso NF, de Groen PC, Menon KV, Lazaridis KN, Gores GJ, Charlton MR, Roberts RO, Therneau TM, Katzmann JA, Roberts LR (2007) The utility of Lens culinaris agglutinin-reactive alpha-fetoprotein in the diagnosis of hepatocellular carcinoma: evaluation in a United States referral population. Clin Gastroenterol Hepatol 5(3): 394-402.

Marrero JA, El-Serag HB (2011) Alpha-fetoprotein should be included in the hepatocellular carcinoma surveillance guidelines of the American Association for the Study of Liver Diseases. Hepatology 53(3): 1060-1061.

Maurer MJ, Cerhan JR, Katzmann JA, Link BK, Allmer C, Zent CS, Call TG, Rabe KG, Hanson CA, Kay NE, Slager SL, Witzig TE, Shanafelt TD (2011) Monoclonal and polyclonal serum free light chains and clinical outcome in chronic lymphocytic leukemia. Blood 118(10): 2821-2826.

Nagao Y, Sata M (2010) Serum albumin and mortality risk in a hyperendemic area of HCV infection in Japan. Virol J 7: 375.

Poon TC, Yip TT, Chan AT, Yip C, Yip V, Mok TS, Lee CC, Leung TW, Ho SK, Johnson PJ (2003) Comprehensive proteomic profiling identifies serum proteomic signatures for detection of hepatocellular carcinoma and its subtypes. Clin Chem 49(5): 752-760. 
Pugh RN, Murray-Lyon IM, Dawson JL, Pietroni MC, Williams R (1973) Transection of the oesophagus for bleeding oesophageal varices. Br J Surg 60(8): 646-649.

Sangiovanni A, Manini MA, Iavarone M, Romeo R, Forzenigo LV, Fraquelli M, Massironi S, Della CC, Ronchi G, Rumi MG, Biondetti P, Colombo M (2010) The diagnostic and economic impact of contrast imaging techniques in the diagnosis of small hepatocellular carcinoma in cirrhosis. Gut 59(5): 638-644.

Schuppan D, Afdhal NH (2008) Liver cirrhosis. Lancet 371(9615): 838-851.

Schwegler EE, Cazares L, Steel LF, Adam BL, Johnson DA, Semmes OJ, Block TM, Marrero JA, Drake RR (2005) SELDI-TOF MS profiling of serum for detection of the progression of chronic hepatitis $\mathrm{C}$ to hepatocellular carcinoma. Hepatology 41(3): 634-642.

Sterling RK, Jeffers L, Gordon F, Sherman M, Venook AP, Reddy KR, Satomura S, Schwartz ME (2007) Clinical utility of AFP-L3\% measurement in North American patients with HCV-related cirrhosis. Am J Gastroenterol 102(10): 2196-2205.

Terrier B, Sene D, Saadoun D, Ghillani-Dalbin P, Thibault V, Delluc A, Piette JC, Cacoub P (2009) Serum free light chain assessment in hepatitis C virus-related lymphoproliferative disorders. Ann Rheum Dis 68(1): 89-93.

Torzilli G, Minagawa M, Takayama T, Inoue K, Hui AM, Kubota K, Ohtomo K, Makuuchi M (1999) Accurate preoperative evaluation of liver mass lesions without fine-needle biopsy. Hepatology 30(4): 889-893. van der Heijden M, Kraneveld A, Redegeld F (2006) Free immunoglobulin light chains as target in the treatment of chronic inflammatory diseases. Eur J Pharmacol 533(1-3): 319-326.

Ward AM, Sheldon J, Rowbottom A, Wild GD (2004) PRU Handbook of Clinical Immunochemistry. PRU Publications: Rotherham, UK.

Ward DG, Cheng Y, N'Kontchou G, Thar TT, Barget N, Wei W, Billingham LJ, Martin A, Beaugrand M, Johnson PJ (2006a) Changes in the serum proteome associated with the development of hepatocellular carcinoma in hepatitis C-related cirrhosis. Br J Cancer 94(2): 287-292.

Ward DG, Cheng Y, N'Kontchou G, Thar TT, Barget N, Wei W, Martin A, Beaugrand M, Johnson PJ (2006b) Preclinical and post-treatment changes in the HCC-associated serum proteome. Br J Cancer 95(10): 1379-1383.

Wong VW, Chan SL, Mo F, Chan TC, Loong HH, Wong GL, Lui YY, Chan AT, Sung JJ, Yeo W, Chan HL, Mok TS (2010) Clinical scoring system to predict hepatocellular carcinoma in chronic hepatitis B carriers. J Clin Oncol 28(10): 1660-1665.

This work is published under the standard license to publish agreement. After 12 months the work will become freely available and the license terms will switch to a Creative Commons AttributionNonCommercial-Share Alike 3.0 Unported License. 